\title{
CREMOR: CREdibility Model on Online Reviews-How people Consider Online Reviews Believable
}

\author{
Patrizia Grifoni ${ }^{1}$, Fernando Ferri ${ }^{1}$, Tiziana Guzzo ${ }^{1}$ \\ ${ }^{1}$ Institute for Research on Population and Social Policies, National Research Council, Italy \\ Correspondence: Fernando Ferri, Institute for Research on Population and Social Policies, National Research \\ Council, Italy.
}

Received: April 20, 2017

Accepted: June 2, 2017 Online Published: June 12, 2017

doi:10.5539/ibr.v10n7p56

URL: https://doi.org/10.5539/ibr.v10n7p56

\begin{abstract}
The Internet is deeply changing how buyers and sellers interact in the marketplace. The Web enables consumers to be informed on their purchases both online and offline thanks to crowdsourced reviews. However, recent studies have found evidence that online consumers review could be not truthful as some users such as owners, competitors, paid users, sometimes post fake reviews. In this context the question of credibility is becoming more and more relevant in the Web 2.0 environment in which the concepts of social influence and electronic word of mouth are acquiring a great importance. The user's perception of online reviews can influence source credibility and the perception of the quality of a product/service, as well as the likelihood that someone will purchase the product/service. This study proposes a model that analyses elements that influence online information credibility and the impact of the perceived credibility on purchase intention.
\end{abstract}

Keywords: credibility, website quality, advisor credibility, customer perception

\section{Introduction}

With the development of Web 2.0 and the revolution in user-computer paradigm, represented by the user generated content - UCG, users are increasing their role of prosumers, i.e. producers and consumers providing more generally an added value in terms of information and services.

Moreover, with the development of social media like social networks, blogs, forums, a strong weight in influencing people behaviors is given by the other people opinions and suggestions, particularly in the case of consumers' decision. These tools are in fact, significantly changing the consumers-retailers relationship offering new potentialities not available in traditional channels and, facilitating user's collaboration and opinions' sharing (Guzzo, Ferri, \& Grifoni, 2014a). Consumers can easily obtain information about products from a large and geographically dispersed population; the resulting electronic word of mouth and its easy access are increasingly important in affecting consumer's decisions. Consumers usually ask their friends or belonging social group opinions before making an online purchase, because they perceive a higher risk in this kind of purchases respect to traditional ones. (Ferri, Grifoni, \& Guzzo, 2008). In this scenario the development of Digital Ecosystems and Internet are playing a crucial role, furtherly stimulating a development of on line marketing defining "symmetry of companies and consumers in their communication process" (Ferri et al., 2014). Indeed, consumers do not passively receive marketers' messages; they actively express their needs, preferences and choices and, ask their friends' opinions and read online reviews. The Web changed old models of word of mouth marketing based on one-to-one relationships, providing a model based on one-to-many amplification of key brand messages, information and reviews from customers (Caschera, Ferri, Grifoni, \& Guzzo, 2009).

In an online marketplace, buyers rely heavily on reviews posted by other consumers. According to Li, Huang, Tan, \& Wei (2013), 92\% of online consumers read reviews before an online purchase. Several studies found that online reviews influenced consumers' decisions (Li et al., 2013; Park, Lee \& Han, 2007). At the basis of this there is the matter of persuasiveness of the online reviews that is determined by credibility.

All these concepts are widely and successfully applied within the online travel communities. This is a virtual community where backpackers, globetrotters, and other people from all over the world join together using different online platforms to exchange information, experiences, and plans in their favorite pursuit travel. In fact, in the travel and tourist industry, Internet encouraged more and more people to join into virtual communities to 
satisfy their needs, to fulfill their asking tips and suggestion before having a "real" travel. This aspect is very important because consumers search information and advices by real travelers to select the best option (Ferri et al. 2008). Users are aware that when they are visiting a business site they usually do not receive cons of a choice. This has produced the availability of Web sites where users share their own travel experiences with other tourists. In fact, usually they prefer to read reviews of other tourists that already visited a place. (Guzzo, D'Andrea, Ferri, \& Grifoni, 2013). In this context the credibility has become a major concern in the current Web 2.0 environment in which the concepts of social influence and electronic word of mouth - eWOM are acquiring a great importance. Fan et al., (2013) found that the decision-making process of consumers is influenced by the information content received and, eWOM changes consumers' attitude toward products and helps them to make purchase decisions.

Starting from these issues, this study introduces a theoretical model containing the elements that influence online information credibility and the impact of the perceived credibility on purchase intention.

The paper is organized as follows: in Section 2, the motivation of the study is explained. Section 3 introduces the methodology used in the study. In section 4, an analysis on credibility and the different variables considered in the model is provided. In section 5, the CREdibility Model on Online Reviews - CREMOR is described. Finally, section 6 concludes the paper.

\section{Background}

Tens of millions of consumers use the online travel forums and review sites to post and share their travel experiences, opinions and comments (Lee, Law, \& Murphy, 2011). For example, Trip Advisor attracts more than 280 million visitors each month (Schoettle, 2014). Moreover, three quarters of consumers have consulted online reviews for their travel decisions (Yoo and Gretzel, 2008; Mauri and Minazzi, 2013). Web sites such as Amazon, TripAdvisor and Yelp depend on online reviews of consumers. Consumers are becoming more independent from intermediaries by searching on the Web destinations and reading information and comments of other users. They use online review to reduce uncertainty and perceived risk during online shopping. Werthner and Ricci (2004 p. 101) noted that "a new type of user is emerging, one who acts as his or her own travel agent and builds a personalized travel package".

However, the online reviews written by wisdom of crowds sometimes could be not truthful, and sometime provide inaccurate or fraudulent information; sometimes they could not have been made by a crowd, and consumers could over-rate or under-rate a product or service for different motivations, such as:

- Good reviews could be written by owners who post positive reviews about themselves to increase business. For example: few excellent reviews and high ratings for hotels that have hundreds of very bad reviews, generally written by anonymous users with one or two reviews in their profile.

- Bad reviews could be written by not real buyers, but by a person who wants to take the advantage of a bad review, such as competitors that post bad recommendations to reduce business from that company. For example: in a hotel with hundreds of excellent ratings only few are extremely negative and generally written by anonymous users.

- Reviews could be written by consumers paid by the merchants and/or by consumer review websites. This aspect can influence the reviewer's opinion. For example: excellent reviews written by anonymous reviewers who in their profile have only extremely positive reviews and generally acclaim owners and staff.

- Bad reviews could be written by users who had a negative experience, or inexperience in buying similar products. For example: some reviewers criticize some irrelevant aspects that actually don't influence the quality of the hotel, because they don't have parameters to judge a hotel because they never traveled. Furthermore it is evident that a hotel with two stars has different standard of a hotel with four or five stars. It depends on the preliminary choice of the hotel's parameters.

Starting from these considerations there is the need to identify and analyse the elements that influence user credibility on online reviews to predict and explain consumer behavior in a rapidly changing environment.

Previous studies were in disagreement on the credibility of online information and its impact on consumer behaviour. According to some studies, online information is more credible than information from other more traditional media (Park et al. 2007; Senecal and Nantel, 2004) because the information is posted by experienced travelers, and then are credible sources (Gretzel, Yoo, \& Purifoy, 2007; Park et al. 2007). According to others studies instead online information can be posted by any individual and therefore is less credible than other types of information sources (Litvin, Goldsmith \& Pan, 2008; Mack, Blose \& Pan, 2008; Magnini, 2011). Different 
studies analysed in particular contents of reviews and the characteristics of reviewers. For example, the review content was judged by its readability that is to how easily the text could be understood by readers (Tausczik \& Pennebaker, 2010). Some studied have underlined the importance of the source expertise and trustworthiness factors in determining credibility (Tseng and Fogg 1999; O'Keefe 2002; Pornpitakpan 2004; Yoo and Gretzel, 2008). Kusumasondjaja, Shanka, \& Marchegiani (2012) found that the review valence and the reviewer's identity impact on the perception of credibility. Similarly Xie, Miao, Kuo, \& Lee (2011) found that hotel reviews with reviewer's identity were perceived as being more credible. Also reviewer's travel experience plays an important role in credibility (Gretzel et al. 2007; Sidali, Schulze, \& Spiller, 2009).

In this paper we take into account besides reviews and reviewer's characteristics (Advisor Credibility), other elements that are related to the credibility process, such as the Website Quality that provides information and, Customer Perception. Therefore, starting from literature evidences we consider three main elements: Advisor Credibility, Website Quality, and Customer Perception. In the next sections, these elements are analysed in detail from a review of the literature and, a theoretical model that systemizes them is proposed.

\section{Method}

In this study we used a deductive method drawing general assumptions derived from theoretical reflections. "The deductive approach follows the path of logic most closely. The reasoning starts with a theory and leads to a new hypothesis. This hypothesis is put to the test by confronting it with observations that either lead to a confirmation or a rejection of the hypothesis" (Snieder and Larner, 2009, p.16).

We started formulating some assumptions (see section 3.1), then we carried out an analysis of literature to strengthen them. Finally, we built a theoretical model by introducing some variables related with credibility and social influence. Indeed, we focus this study on the different aspects of online credibility reviews for online purchases.

\subsection{Assumptions}

We started from the assumption that when people take a decision without a specific knowledge, usually just look at what others are doing and act accordingly. For example, people tend to behave and dress in a certain way because they feel that they are part of a whole.

Generally, people tend to consider more reliable and favorably welcome the opinion of people who know or are considered leaders or experts in that field. Moreover, the positive testimony of online reviews and other users' votes on the product they would like to buy is a strong persuasive element for promoting purchase. But, which are factors that determine if an online review is credible or not?

Starting from the previous examples, we assume that there are three main elements that act in the process of user's credibility and impact in influencing online purchases. These elements are related to:

- The Website that provides information: Website Quality, it includes Information Quality and Reputation/Brand.

- The person who writes the reviews: Advisor credibility, it includes Expertise of reviewer; Readability of reviews.

- The consumer that consults the reviews: Customer perception,it includes Perceived Trustworthiness, Consumer experience and satisfaction.

In the next section these assumptions are detailed providing the theoretical foundations for the model described in section 5 .

\section{Credibility}

Credibility was defined as believability of information and its source (Hovland, Janis, \& Kelley, 1953). It plays a crucial role in persuasion process. In information science, it is one of the criteria of relevance judgment used in the decision process to accept or reject retrieved information (Riehand Danielson, 2007). It depends on characteristics of persuasive sources, characteristics of the message structure and content, and perceptions of media (Metzger, Flanagin, Eyal, Lemus, \& McCann, 2003). The positive characteristics of a message can enhance the perceived value of message information, and can increase the persuasiveness of the message (Rezaei, 2015; Mcallister, 1997). According to Fogg et al. (2003), credibility is related to a perception, then it depends on evaluation of people, then it is subjective.

In the tourism context, the concept of credibility assumes a great relevance due to the intangible nature of tourism products that don't allow evaluating before purchase and risks associated with decision making (Loda, 
Teichmann \& Zins, 2009; Ayeh, Au, \& Law, 2013) examined travel consumers' perceptions regarding the credibility of user generated contents sources and how such perceptions may influence attitudes and intentions toward UGC utilization for travel planning. This study found the central mediating role of attitude and homophily as a critical determinant of both credibility and attitude.

According to different authors, the most relevant dimensions of credibility are trustworthiness, expertise and advisor credibility (Tseng and Fogg 1999; O'Keefe 2002; Pornpitakpan 2004; Yoo and Gretzel, 200 8). Cheung, Sia \& Kuan (2012) found that argument quality was the primary factor affecting the credibility of online reviews; other minor factors are source credibility and review consistency.

Which are elements that influence credibility process? In the next section the main elements: i) Website Quality, ii) Advisor Credibility, and iii) Customer Perception, are described in detail.

\subsection{Website Quality}

Website Quality is the most important element that affects online information credibility. In fact, the customers' perceptions of website quality positively impact their intentions to use a site (Chang and Chen, 2008) and directly affect purchase intentions (McKnight, Choudhury, \& Kacmar, 2002).

According to Lin (2007) "website quality is a multi-dimensional construct comprising information quality, system quality, and service quality." Both information and system quality are defined from a technical perspective while service quality is defined from a customer-oriented perspective. The main variables that compose this element are: Information Quality and Reputation/Brand.

Information quality is related to usefulness, goodness, accuracy, currency, and importance (Rieh, 2002). These aspects are not always present in information, and then people ask themselves whether they can take information seriously. Information quality is a key aspect of online information credibility in order to make effective decisions on purchases. The advantage of online reviews is that they reduce the cost for search information supporting consumers in their decision making process. According to Gobinath and Gupta (2016) when there is information overload, that is abundant quantity of information or very high quality of information, it tends to decrease the decision effectiveness of the consumer. But also in the case in which information quality is below average it limits the effectiveness of the decision. Then, information of good quality is needed for users to make effective decisions.

Website brand is one of the fundamental variables that increases perceived trust and helps to maintain long-term customer relationships on the Internet (Hashim and Murphy, 2007). The brand is a symbol of a firm's name, which stands for the difference between other competitors. According to Chang and Chen (2008) there are two dimensions of website brand: website awareness and website image. Website awareness refers to awareness generated by a Website on the customers. People in fact think that a well-known website is more likely to complete their needs. Website image is defined instead as, "the perceptions about a website name as reflected by the website associations held in customer memory."

When brand reputation is good, it meets the predictability of customer and it can satisfy the customer's needs and helps to develop trust of customer on brand (Afzal, Khan, ur Rehman, Ali, \& Wajahat (2010). Website brand has in fact an impact on consumer's trust then on their purchase intentions (Fam, Foscht, \& Collins, 2004; Romaniuk and Sharp, 2003). For example, when customers intend to book online a hotel room, the hotels which provide high website quality and customers evaluations of brands will evoke more positive customers' trust toward the hotel website and facilitate their decision to purchase it (Chang et al., 2014).

\subsection{Advisor Credibility}

Another important element that affects online information credibility is Advisor Credibility. The main variables that compose this element are: Expertise of reviewer; Readability of reviews.

Expertise of reviewer is an important variable of Advisory Credibility. Expertise is "the perceived knowledge, skill, and experience of the source" (Fogg, 2003a, p. 124). It is related to the ability of a source to provide information both correct and valid, people trust information when sources have expertise (Rezaei, 2015).This capability can be technical-oriented or practical-oriented (Dunn and Schweitzer, 2005). Technical expertise is the skill related to a specialised knowledge required by writing comments towards a given product. Practical expertise is the skills gained from direct participation in related activities (e.g., an advisor who has tried a product or/and a service).

The limited availability of personal information makes difficult to identify whether an advisor is an expert or not. Information on advisors' identity such as real name, gender, location, nickname, hobbies and reputation helps 
consumers' judgment (Park, Xiang, Josiam, \& Kim, 2013; Forman, Ghose, Wiesenfeld, 2008; Ghose and Ipeirotis, 2011). Also the number of reviews written on a service or product can be an element that can create bias in the consumer's decision making.

Understanding is another important factor that affects consumers' credibility of online review. The readability is the degree to which a piece of text is understandable to readers based on its syntactical elements and style. Reviews with high readability, precise or easy to understand, are more reliable than reviews with low readability, that is, the review source is more credible.

\subsection{Customer Perception}

Customer Perception is an essential element in the credibility process. Variables that affect it are: Perceived Trustworthiness, Consumer experience and satisfaction.

Trustworthiness describes the receiver's confidence in a source's objectivity and honesty in providing information (Rezaei, 2015).

Trustworthiness of advisors' review is based on:

- Similarity: a buyer has an increased trust towards an advisor who has similar preferences and opinions into the same social group (Jindal, Liu, Lim, 2010; Ziegler and Golbeck, 2007).

- Social consensus: a review is perceived as correct if advisor has the same opinions of the majority of advisors (Zhang and Cohen, 2008).

- Social network: dishonest advisors (e.g., fake buyers' accounts), may share the same review behavioral pattern (Zhu, Zhang \& Yu, 2011).

Reviews can be written by advisors that are able to assess a product critically or not then both by laypersons and experts. Different factors can influence the writing of a review. He can be paid by a seller to write positive or negative reviews, or he can be influenced by opinions of others reviewers (herd effect) (Sprecker, 2002; Zhang Bian \& Zhu (2012). To overcame this issue some online marketplaces (e.g., Amazon, Taobao) enable buyers to visit profile information of advisors such as real name, location, nickname and hobbies. This information is useful for consumers' judgment of advisors' credibility. According to Kusumasondjaja et al. (2012), when the identity of the reviewer is disclosed, negative online review is more credible than a positive online review, while a positive online review leads to a greater initial trust than a negative review, when instead the identity of the reviewer is not disclosed, there is no significant difference.

Consumer experience in reading and evaluating online reviews, and satisfaction with a service and/or product, which consumers trusted reviews, are very important variables that affect a successful long-term relationship with online information credibility. Judgments are subjective and they can vary according to single attitude of reviewer. In this context the consumer experience is fundamental to evaluate reviews. For example a reviewer with low experience can give high ratings and the content of the review contains some aspects that for other consumers could be very critical and the rating could be very lower. Then it is very important to know how evaluate reviews.

Another important element to take into account is satisfaction. It is users' feelings about past online shopping experiences (Bhattacherjee, 2001). Chang, Cheung, \&Lai (2005) define satisfaction as the consumer confirmation of expectations based on their experiences and the perceived usefulness from the initial use of an information system. It is a strong predictor of continuance to use than perceived usefulness because the effect of the latter decreases over the time (Devaraj, Fan, \& Kohli, 2003). Zhou, Dai, \& Zhang (2007) considered satisfaction as an extension to address the long-term continuance of online shopping. If people were satisfied from their previous experiences in reading online reviews are more likely to trust them.

\section{Theoretical Credibility Model}

This section describes the theoretical credibility model on the basis of the evidences from literature (summarized in table 1). 
Table 1. Summary of analysed literature

\begin{tabular}{|c|c|}
\hline & Literature Review \\
\hline $\begin{array}{l}\text { WEBSITE QUALITY } \\
\text { (Information Quality; } \\
\text { Reputation/Brand) }\end{array}$ & $\begin{array}{l}\text { Website quality is a multi-dimensional construct comprising } \\
\text { information quality, system quality, and service quality. It } \\
\text { positively impacts customers' intentions to use a site. } \\
\text { Information quality is related to usefulness, goodness, accuracy, } \\
\text { currency, and importance and it affects people to make decisions } \\
\text { on purchases. } \\
\text { Information overload or little information decreases the decision } \\
\text { effectiveness of the consumer. } \\
\text { Website brand impacts consumer's trust then their purchase } \\
\text { intentions. It helps to maintain long-term customer relationships } \\
\text { on the Internet. }\end{array}$ \\
\hline
\end{tabular}

Website awareness and website image increase people trust because they think that a well-known website is more likely to complete their needs.

$\begin{array}{ll}\text { ADVISOR } & \begin{array}{l}\text { People trust information when sources have expertise that is the } \\ \text { CREDIBILITY }\end{array} \\ \text { ability of a source to provide information both correct and valid. } \\ \text { Readability of reviews) } & \begin{array}{l}\text { The limited availability of personal information doesn't allow } \\ \text { identify whether an advisor is an expert and influence } \\ \text { consumer's decision making. }\end{array}\end{array}$

The readability is related to understanding; high readability influences consumers' credibility of online review.
CUSTOMER PERCEPTION

(Perceived

Trustworthiness;

Consumer experience;

Satisfaction)
Trustworthiness describes the receiver's confidence in a source's objectivity and honesty in providing information.

Trustworthiness is based on similarity (advisor who has similar purchase history and review opinions into the same social group).

Trustworthiness is based on social consensus (advisor has the same opinions of the majority of advisors).

Trustworthiness is based on social network (dishonest advisors, like fake buyers' accounts, may share the same review behavioral pattern).

Consumer experience in reading and evaluating online reviews affects online information credibility

Satisfaction is a variable that affects the long-term continuance of online shopping.
Lin, 2007; Chang and Chen, 2008.

Rieh, 2002; McKnight et al. 2002.

Gobinath and Gupta, 2016.

Fam et al., 2004; Romaniuk and Sharp, 2003; Hashim and Murphy, 2007; Afzal et al., 2010.

Chang and Chen, 2008.

\section{Rezaei, 2015.}

Kusumasondjaja et al. 2012; Park et al., 2013; Forman et al., 2008; Ghose and Ipeirotis, 2011

Korfiatis, et al. 2012.

Rezaei, 2015.

Jindal et al., 2010; Ziegler and Golbeck, 2007.

Zhang and Cohen, 2008.

Zhu et al., 2011.

Sprecker, 2002; Zhang et al., 2012.

Devaraj et al., 2003; Zhou et al., 2007.

Starting from literature evidences, we consider the following three elements: i) Website Quality, ii) Advisor Credibility, iii) Customer Perception as variables that affect credibility process in online purchases.

Figure 1 shows the theoretical model that explains user's behavior and credibility process.

The CREMOR model is based on the idea that the process of credibility of online reviews is affected by different elements and variables as represented in figure 1. The model starts with the purchase intention that depends on the one hand from personal motivations of people and on the other by social influence from the circle of friends and contacts and within social networks environments that suggest doing the same purchase. Moreover if people have intention to purchase something ask for opinions to their contacts that have already purchased that product or service. When a user has intention to do an online purchase generally read online reviews written by other users. In this process three main elements have to be considered: 1) the Website that provides information: Website Quality, 2) the person who writes the reviews: Advisor Credibility and, 3) the consumer that consults the reviews: Customer Perception. The variables that compose these elements act as variables of input in the process of user's credibility. In particular, the variables concerning Website Quality to take into account in the process of credibility are: i) Information quality present in the Website that has to be useful, good, accurate, current, and important, and ii) Reputation of the Website and Brand that is related to website awareness and website image that affect customers' trust. Another important element to take into account is that related to Advisor Credibility, in particular: i) Expertise of reviewer, its knowledge, skill and ability of providing information both correct and valid, and ii) Readability of reviews based on their understanding. Last but not least, another important element is that concerning Customer Perception; the variables that compose it are: i) Perceived trustworthiness related to the consumer's confidence in a source's objectivity and honesty in providing information, ii) Experience of consumer in reading and evaluating online reviews and, iii) Satisfaction of past purchases by using the same Website for online reviews. 


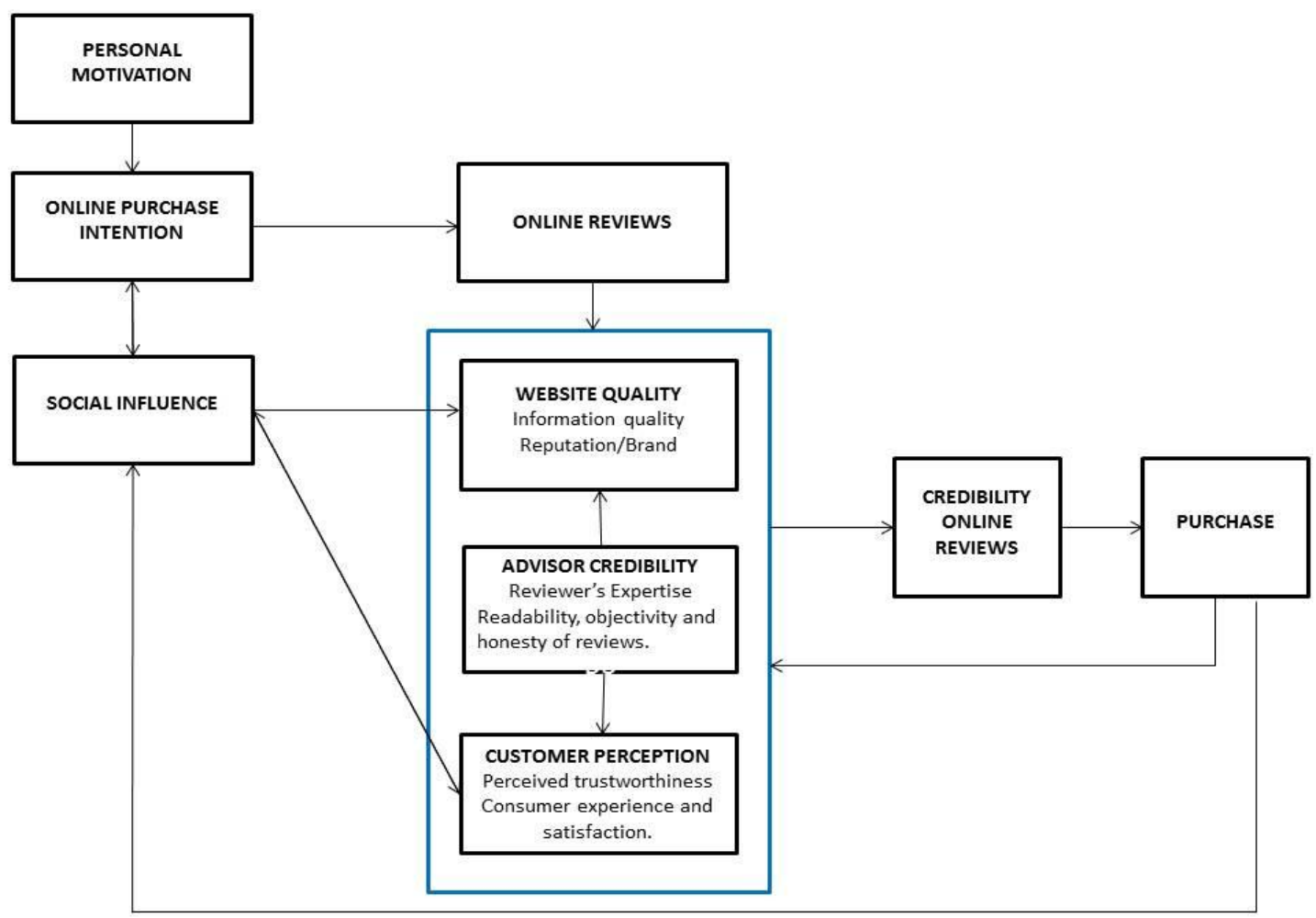

Figure 1. CREdibility Model on Online Reviews - CREMOR

Advisor Credibility is a central element because it influences both Website Quality and Customer Perception. That is, if reviews are well written and information provided from them is good, this increases the quality of Website. In the same time, the quality of reviews influences user's perception and credibility and then their behaviors. Moreover, Customer Perception is also affected by Social Influence, in fact, opinions of other people and in particular people of own social circle who people trust, are very important in the decision process. Consumers can really modify their opinions about products and/or services according to the social influence process, this process also impacts on knowledge diffusion about products and services (Ferri, Grifoni, \& Guzzo, 2013; Guzzo, Ferri, \& Grifoni, 2014b; Guzzo, Ferri, \& Grifoni, 2016). Website Quality is also affected by Social Influence because reputation of a website depends on also by word of mouth of people.

All these elements affect the credibility process of online reviews then the resulting purchase. To the end of the process, when the consumer purchases he validate or not the previous process that led to him to perceive as credible the online reviews and in the same time influences other consumers on the basis of its experience, then the process restarts.

\section{Conclusion}

The paper, starting from some evidences of literature, proposes a theoretical model: the CREdibility Model on Online Reviews - CREMOR that introduces some variables affecting the process of online information credibility in the context of online purchases.

We assume that there are three main elements that act in the process of user's credibility and impact in influencing online purchases. These elements are related to 1) Website that provides information (Website Quality), 2) the reviewer that writes the reviews (Advisor Credibility), 3) the consumer that consults the online reviews (Customer Perception). The elements that act in the process of user's credibility and impact in influencing online purchase are:

- Website Quality: the quality of the media used is fundamental in the credibility process. In particular an important role is assumed by two variables: i) Information Quality that is the provided information that have to be useful, good, accurate, current, and important and ii) Reputation/Brand of the Web site that is related to website awareness and website image that affect customers' trust. 
- Advisor credibility: the credibility of the reviewer is related to i) the expertise of the reviewer that is the knowledge, skill and ability of a source to provide information both correct and valid and ii) readability of reviews that is the understanding of a text based on its syntactical elements and style.

Customer Perception: the perception of the consumer that consults the reviews is affected by the variables: i) Perceived Trustworthiness that is the consumer's confidence in a source's objectivity and honesty in providing information ii) Consumer experience in reading and evaluating online reviews and iii) satisfaction with a service and/or product, which consumers trusted reviews.

The sum of the previous variables acts on user's credibility and then on the online purchase.

The study carried out focuses on a theoretical model building, on the basis of a literature review. In a future study it will be tested by using data collected from a survey with a quantitative approach.

The CREMOR model has some practical implications. First, it contributes to a better understanding of the user's credibility process of online information provided by online reviews. Second, this model can be used for defining the marketing strategies of companies evaluating variables that influence people in the credibility process.

\section{References}

Afzal, H., Khan, M. A., urRehman, K., Ali, I., \& Wajahat, S. (2010). Consumer's trust in the brand: Can it be built through brand reputation, brand competence and brand predictability. International Business Research, 3(1), 43.

Ayeh, J. K., Au, N., \& Law, R. (2013). Do we believe in TripAdvisor? Examining credibility perceptions and online travelers' attitude toward using user-generated content. Journal of Travel Research. https://doi.org/10.1177/0047287512475217

Bhattacherjee, A. (2001). Understanding Information Systems Continuance: An Expectation Confirmation Model. MIS Quarterly, 25(3), 351-370.https://doi.org/10.2307/3250921

Caschera, M. C., Ferri, F., Grifoni, P., \& Guzzo, T. (2009, April). Multidimensional visualization system for travel social networks. Information Technology: New Generations, 2009. ITNG'09. Proceedings of the of the Sixth International Conference (pp. 1510-1516). IEEE. https://doi.org/10.1109/itng.2009.236

Chang, H. H., \& Chen, S. W. (2008). The impact of online store environment cues on purchase intention: Trust and perceived risk as a mediator. Online Information Review, 32(6), 818-841. https://doi.org/10.1108/14684520810923953

Chang, M. K., Cheung, W., \& Lai, V. S. (2005). Literature Derived Reference Models for the Adoption of Online Shopping. Information \& Management, 42, 543-559. https://doi.org/10.1016/S0378-7206(04)00051-5

Cheung, C. M. Y., Sia, C. L., \& Kuan, K. K. (2012). Is this review believable? A study of factors affecting the credibility of online consumer reviews from an ELM perspective. Journal of the Association for Information Systems, 13(8), 618.

Devaraj, S., Fan, M., \&. Kohli, R. (2003). E-Loyalty: Elusive Ideal or Competitive Edge? Communications of the ACM, 46(9), 184-191. https://doi.org/10.1145/903893.903936

Dunn, J. R., \& Schweitzer, M. E. (2005). Feeling and believing: the influence of emotion on trust. J Pers Soc Psychol, 88(5), 736. https://doi.org/10.1037/0022-3514.88.5.736

Fam, K. S., Foscht, T., \& Collins, R. D. (2004). Trust and the online relationships: An exploratory study from New Zealand. Tourism Management, 25(2), 195-207. https://doi.org/10.1016/S0261-5177(03)00084-0

Fan, Y. W., Yi, F. M., Yu, H. F., \& Ruei, Y. L. (2013) Establishing the adoption of electronic word-of-mouth through consumers' perceived credibility. International Business Research, 6(3), 58. https://doi.org/10.5539/ibr.v6n3p58

Ferri, F., Grifoni, P., \& Guzzo, T. (2008). Social Aspects of Mobile Technologies on Web Tourism Trend. Handbook of research on mobile business: technical, methodological and social perspectives, 293-303.

Ferri, F., Grifoni, P., \& Guzzo, T. (2013). Factors determining mobile shopping. A theoretical model of mobile commerce acceptance. International Journal of Information Processing and Management (IJIPM), 4(7), 89-101.

Ferri, F., Grifoni, P., Caschera, M. C., D'Andrea, A., D’Ulizia, A., \& Guzzo, T. (2014, September). An 
ecosystemic environment for knowledge and services sharing on creative enterprises.Proceedings of the 6th International Conference on Management of Emergent Digital EcoSystems (pp. 27-33). ACM. https://doi.org/10.1145/2668260.2668308

Fogg, B. J. (2003). Persuasive Technology: Using Computers to Change What We Think and Do. Boston, MA: Morgan Kauffman Publishers.

Forman, C., Ghose A., \& Wiesenfeld, B. (2008).Examining the relationship between reviews and sales: The role of reviewer identity disclosure in electronic markets. InfSyst Res, 19(3), 291-313. https://doi.org/10.1287/isre.1080.0193

Ghose, A., \& Ipeirotis, P. G. (2011). Estimating the helpfulness and economic impact of product reviews: Mining text and reviewer characteristics. IEEE Trans Knowl Data Eng, 3(10), 1498-1512. https://doi.org/10.1109/TKDE.2010.188

Gobinath, J., \& Gupta, D. (2016). Online reviews: Determining the perceived quality of information. Advances in Computing, Communications and Informatics (ICACCI), Proceedings of the International Conference (pp. 412-416). IEEE. https://doi.org/10.1109/icacci.2016.7732080

Gretzel, U., Yoo, K. H., \& Purifoy. (2007). M.: Online Travel Review Study: Role and Impact of Online Travel Reviews. Laboratory for Intelligent Systems in Tourism, Texas A\&M University.

Guzzo, T., D'Andrea, A., Ferri, F., \& Grifoni, P. (2013, January). A framework to promote and de velop a sustainable tourism by using social media. In On the Move to Meaningful Internet Systems: OTM 2013 Workshops (pp. 656-665). Springer Berlin Heidelberg. https://doi.org/10.1007/978-3-642-41033-8_83

Guzzo, T., Ferri, F., \& Grifoni, P. (2014a). ECA: An E-commerce consumer acceptance model. International Business Research, 8(1), 145. https://doi.org/10.5539/ibr.v8n1p145

Guzzo, T., Ferri, F., \& Grifoni, P. (2014b).Social influence analysis.In Encyclopedia of Social Network Analysis and Mining (pp. 1800-1807).Springer New York. https://doi.org/10.1007/978-1-4614-6170-8_186

Guzzo, T., Ferri, F., \& Grifoni, P. (2016). A model of e-commerce adoption (MOCA): consumer's perceptions and behaviours. Behaviour\& Information Technology, 35(3), 196-209. https://doi.org/10.1080/0144929X.2015.1132770

Hashim, N. H., \& Murphy, J. (2007).Branding on the web: evolving domain name usage among Malaysian hotels. Tourism Management, 28(2), 621-624. https://doi.org/10.1016/j.tourman.2006.09.013

Hovland, C., Janis, I., \& Kelley, H. (1953).Communication and persuasion: Psychological studies of opinion change.NewHaven, CT: Yale University Press.

Jindal, N., Liu B., \& Lim, E. P. (2010). Finding unusual review patterns using unexpected rules. Proceedings of the 19th ACM international conference on Information and knowledge management, ACM, New York, 1549-1552. https://doi.org/10.1145/1871437.1871669

Korfiatis, N., Garcia-Bariocanal, E., \& Sanchez-Alonso, S. (2012). Evaluating content quality and helpfulness of online product reviews: The interplay of reviews helpfulness vs. review content.Electronic Commerce Research and Applications, 11(3), 205-217. https://doi.org/10.1016/j.elerap.2011.10.003

Kusumasondjaja, S., Shanka, T., \& Marchegiani, C. (2012).Credibility of online reviews and initial trust.The roles of reviewer's identity and review valence. Journal of Vacation Marketing, 18(3), 185-195. https://doi.org/10.1177/1356766712449365

Lee, H., Law, R., \& Murphy, J. (2011) Helpful reviewers in TripAdvisor, an online travel community. Journal of Travel \& Tourism Marketing, 28(7), 675-688. https://doi.org/10.1080/10548408.2011.611739

Li, M., Huang, L., Ta,n C. H., \& Wei, K. K. (2013). Helpfulness of online product reviews as seen by consumers: Source and content features. Int J Electron Commer 17(4), 101-136. https://doi.org/10.2753/JEC1086-4415170404

Lin, H. F. (2007). The impact of website quality dimensions on customer satisfaction in the b2c e-commerce context. Total Quality Management \& Business Excellence, 18(3), 363-378. https://doi.org/10.1080/14783360701231302

Litvin, S. W., Goldsmith, R. E., \& Pan, B. (2008).Electronic word-of-mouth in hospitality and tourism management.Tourism Management, 29(3), 458-468. https://doi.org/10.1016/j.tourman.2007.05.011

Loda, M. D., Teichmann, K., \& Zins, A.H. (2009).Destination websites' persuasiveness. International Journal of 
Culture Tourism and Hospitality Research, 3(1), 70-80.https://doi.org/10.1108/17506180910940351

Mack, R. W., Blose, J., \& Pan, B. (2008). Believe it or not: credibility of blogs in tourism. Journal of Vacation Marketing, 14(2), 133-144. https://doi.org/10.1177/1356766707087521

Magnini, V. P. (2011). The implications of company sponsored messages disguised as word-of-mouth. Journal of Services Marketing, 25(4), 243-251. https://doi.org/10.1108/08876041111143078

Mcallister, D. J. (1997). The second face of trust: Reflections on the dark side of interpersonal trust in organizations. Res Negotiation Organ, 6, 87-111.

McKnight, D. H., Choudhury, V., \& Kacmar, C. (2002). The impact of initial consumer trust on intentions to transact with a web site: A trust building model. The Journal of Strategic Information Systems, 11(3), 297-323. https://doi.org/10.1016/S0963-8687(02)00020-3

Metzger, M. J., Flanagin, A. J., Eyal, K., Lemus, D., \& McCann, R. (2003).Credibility in the 21st century: Integrating perspectives on source, message, and media credibility in the contemporary media environment. Communication Yearbook, 27, 293-335. https://doi.org/10.1207/s15567419cy2701_10

O’Keefe, D. J. (2002). Persuasion: Theory and research. Beverly Hills, CA: Sage.

Park, D. H., Lee, J., \& Han, I. (2007). The effect of online consumer reviews on consumer purchasing intention: the moderating role of involvement. International Journal of Electronic Commerce, 11(4), 125-148. https://doi.org/10.2753/JEC1086-4415110405

Park, H., Xiang, Z., Josiam, B., \& Kim H. (2013). Personal profile information as cues of credibility in online travel reviews. Anatolia, 25(1), 13-23. https://doi.org/10.1080/13032917.2013.820203

Pornpitakpan, C. (2004). The persuasiveness of source credibility: A critical review of five decades' evidence. Journal of Applied Psychology, 34(2), 243-281. https://doi.org/10.1111/j.1559-1816.2004.tb02547.x

Rezaei, S. (2015) Segmenting consumer decision-making styles (cdms) toward marketing practice: A partial least squares (pls) path modeling approach. J Retail Consum Serv 22, 1-15. https://doi.org/10.1016/j.jretconser.2014.09.001

Rieh, S. Y. (2002). Judgment of Information Quality and Cognitive Authority in the Web. Journal of the American Society for Information Science and Technology, 53(2), 145-161. https://doi.org/10.1002/asi.10017

Rieh, S. Y., \& Danielson, D. R. (2007). Credibility: A multidisciplinary framework. Annual Review of Information Science and Technology, 41, 307-364. Medford, NJ: Information Today. https://doi.org/10.1002/aris.2007.1440410114

Romaniuk, J., \& Sharp, B. (2003). Measuring brand perceptions: Testing quantity and quality. Journal of Targeting, Measurement and Analysis for Marketing, 11(3), 218-229. https://doi.org/10.1057/palgrave.jt.5740079

Schoettle, A. (2014). TripAdvisor is a new powerhouse in the hospitality industry. Indianapolis Business Journal. Retrieved from http://www.ibj.com/ articles/50146-tripadvisor-is-new-powerhouse-in-hospitality-industry

Senecal, S., \& Nantel, A. (2004). The influence of online product recommendations on consumers' online choices. Journal of Retailing, 80, 159-169. https://doi.org/10.1016/j.jretai.2004.04.001

Sidali, K. L., Schulze, H., \& Spiller, A. (2009). The impact of online reviews on the choice of holiday accommodations. Information and Communication Technologies in Tourism, 87-98. https://doi.org/10.1007/978-3-211-93971-0_8

Snieder, R., \& Larner, K. (2009).The Art of Being a Scientist: A Guide for Graduate Students and their Mentors. Cambridge University Press. https://doi.org/10.1017/cbo9780511816543

Sprecker, K. (2002). How involvement, citation style, and funding source affect the credibility of university scientists. SciCommun, 24(1), 72-97. https://doi.org/10.1177/107554700202400104

Tausczik, Y. R., \& Pennebaker, J. W. (2010). The psychological meaning of words: LIWC and computerized text analysis methods. Journal of Language and Social Psychology, 29(1), 24-54. https://doi.org/10.1177/0261927X09351676

Tseng, S., \& Fogg, B. J. (1999).Credibility and computing technology. Communications of the ACM, 42(5), 39-44. https://doi.org/10.1145/301353.301402 
Werthner, H., \& Ricci, F. (2004). E-Commerce and Tourism. Communications of the ACM, 47(12), 101-105. https://doi.org/10.1145/1035134.1035141

Xie, H., Miao, L., Kuo, P. J., \& Lee, B. Y. (2011). Consumers' Responses to Ambivalent Online Hotel Reviews: The Role of Perceived Source Credibility and Pre-decisional Disposition. International Journal of Hospitality Management 30(1), 178-183. https://doi.org/10.1016/j.ijhm.2010.04.008

Yoo, K. H., \& Gretzel, U. (2008).The Influence of Perceived Credibility on Preferences for Recommender Systems as Sources of Advice. Journal of IT \& Tourism, 10(2), 133-146.

Yoo, K. H., \& Gretzel, U. (2011).Creating More Credible and Persuasive Recommender Systems: The Influence of Source Characteristics on Recommender System Evaluations. In Recommender Systems Handbook 2011, edited by F. Ricci, L. Rokach, B. Shapira, and P. B. Kantor. New York: Springer, 455-477. https://doi.org/10.1007/978-0-387-85820-3_14

Zhang, J., \& Cohen, R. (2008).Evaluating the trustworthiness of advice about seller agents in e-marketplaces: a personalized approach. Electron Commer Res Appl, 7(3), 330-340. https://doi.org/10.1016/j.elerap.2008.03.001

Zhang, Y., Bian J., \& Zhu, W. (2012). Trust fraud: A crucial challenge for china's e-commerce market. Electron Commer Res Appl, 12(5), 299-308. https://doi.org/10.1016/j.elerap.2012.11.005

Zhou, L., Dai, L., \& Zhang, D. (2007). Online shopping acceptance model-A critical survey of consumer factors in online shopping. Journal of Electronic Commerce Research, 8(1), 41-62.

Zhu, Y., Zhang, W., \& Yu, C. (2011).Detection of feedback reputation fraud in taobao using social network theory. International Joint Conference on Service Sciences (IJCSS). IEEE Computer Society Press, Washington, 188-192.

Ziegler, C. N., \& Golbeck, J. (2007).Investigating interactions of trust and interest similarity. Decis Support Syst, 43(2), 460-475. https://doi.org/10.1016/j.dss.2006.11.003

\section{Copyrights}

Copyright for this article is retained by the author(s), with first publication rights granted to the journal.

This is an open-access article distributed under the terms and conditions of the Creative Commons Attribution license (http://creativecommons.org/licenses/by/4.0/). 